\title{
Comentario sobre el artículo "Causas de mortalidad por enfermedades del aparato respiratorio en Jerez de los Caballeros (Badajoz, España) durante el siglo XIX"
}

\author{
GONZALO VALDIVIA C.
}

Profesor Titular, Departamento de Salud Pública, Pontificia Universidad Católica de Chile.

En este número de la revista, se presenta un interesante artículo que alude a una retrospectiva histórica sobre la relevancia de las enfermedades respiratorias en España ${ }^{1}$, que estimula a un comentario en la misma perspectiva en relación a Chile.

La situación relatada en el artículo original, sorprende por dos razones principales: por la preeminencia de la mortalidad derivadas de estas enfermedades para el contexto histórico analizado (siglo XIX, albores del XX) y por la presencia ya de dichas enfermedades como causa de muerte en población adulta en Jerez de los Caballeros (Bajadoz).

En Chile, el relato acerca de las condiciones de salud y las causas de muertes se reporta a los albores de la República, destacando en cuanto a la mortalidad, el predominio de la mortalidad prematura, focalizada en el primer año de vida, explicada fundamentalmente por las enfermedades transmisibles ${ }^{2}$.

Mucho se ha escrito acerca de la adversa influencia de la conquista, al encontrar un nicho fértil en aborígenes locales, enfermedades endémicas del conquistador, que diezmaron, según versan los reportes, a grandes volúmenes de indígenas de la Araucanía. Dicho efecto, comprometió entre otras enfermedades, pero no exclusivamente, a la tuberculosis pulmonar ${ }^{2,3}$.

Sin embargo, parece ser que las enfermedades respiratorias agudas estaban ya presentes como causa de muerte en los indígenas del norte de nuestro país antes de la llegada de los españoles. Esto, a juzgar por los análisis antropológicos de momias del asentamiento del Chinchorro, Arica, en quienes la frecuencia de lesiones pulmonares agudas de origen neumocócico predominó en el estudio de 108 momias obtenidas del asentamiento señalado estudiado en la Universidad de Tarapacá ${ }^{4}$. Aún más, los autores argumentan que desde hace 2.000 años atrás hay evidencias de ésta y otras enfermedades respiratorias, incluyendo neumoconiosis en mineros desde el siglo XVI, con neumonía como causa probable de muerte entre ellos.
Desde el período de la Colonia a los albores del siglo XIX, la alta mortalidad infantil, evaluada especialmente en grandes ciudades, como Santiago y Concepción, señalaba a las enfermedades respiratorias y enfermedades transmisibles, con complicaciones respiratorias, predominando como principales causas de muerte prematura, detrás del grupo de enfermedades gastrointestinales ${ }^{5}$. Las malas condiciones de vida imperantes, las inadecuadas condiciones sanitarias y el bajo nivel de desarrollo del país, explicaban para la época, la particular demografía de la población chilena, con baja expectativa de vida y predominio de población joven, que en su momento, concentró al $43 \%$ de la población en menores de 15 años ${ }^{6,7}$.

Estas observaciones fueron corroboradas en el año 1927 en el magistral reporte preparado sobre el control de la mortalidad infantil publicado en los albores de la Revista Chilena de Pediatría por el profesor Dr. Luis Calvo Mackenna ${ }^{8}$.

El artículo de Suárez-Guzmán, Peral y Márquez ${ }^{1}$ permite establecer un contrapunto histórico que releva la importancia de las enfermedades respiratorias como causa de muerte fuertemente arraigada en las comunidades, su particular distribución en relación con las condiciones demográficas y epidemiológicas de los países, y la influencia de determinantes sociales y ambientales, como factores que explican la creciente importancia de estas enfermedades observadas en la actualidad en nuestro país?.

\section{Bibliografía}

1.- SUÁREZ-GUZMÁN F, PERAL D, MÁRQUEZ F L. Causas de mortalidad por enfermedades del aparato respiratorio en Jerez de los Caballeros (Badajoz, España) durante el siglo XIX.

2.- FERRER RODRÍGUEZ P L. Historia general de la Medicina en Chile. Desde el descubrimiento y conquista de Chile en 1535 hasta nuestros días. Tomo primero. Desde 1535 hasta la inauguración de la Universidad de Chile en 1843. Talca, 1904 Colección: Biblioteca Nacional de 
Chile. (descargable desde: http://www.memoriachilena. cl/602/w3-article-98488.html). Consultada el 27 octubre de 2015.

3.- SÁEZ J. Impacto del contacto hispano-indígena en la salud de la población de Chiloé. Un caso de tuberculosis en el cementerio Puqueldón. Magallania, (Chile), 2008; 36: 167-74.

4.- FONTANA D, MARVIN A, GERTSZEN E, ARRIAZA B. Enfermedades respiratorias agudas en los habitantes precolombinos del norte de Chile. Revista Chungará 1983; 153-160. Universidad de Tarapacá, Chile.

5.- ÁLVAREZ J. Primaria infancia: un concepto de la modernidad. El observador 2011; 7: 62-74.
6.- SALINAS MEZA R. América Latina en la historia contemporánea. Población y sociedad. Chile 1880-1930. Fundación Mapfre. 2015, España.

7.- FERNANDOIS J, ESTRADA B. América Latina en la historia contemporánea. Chile; la apertura al mundo. Tomo 3 Fundación Mapfre, 2015, España.

8.- SCHONHAUT L. La mortalidad infantil en Chile. Estudiada por la Sociedad de las Naciones. Publicado por Luis Calvo Mackenna en la Revista Chilena de Pediatría 1930. Rev Chil Pediatr 2007; 78: 204-12.

9.- VALDIVIA G. Hacia el control radical de las enfermedades respiratorias: un alto en el camino. Rev Chil Enferm Respir 2015; 31: 5-7.
Correspondencia a:

Dr. Gonzalo Valdivia Cabrera

Médico Especialista en Salud Pública

Profesor Titular. Departamento de Salud Pública

Pontificia Universidad Católica de Chile.

Email: valdiviacg@gmail.com 